\title{
Virginia WoOlf e A Fotografia ${ }^{1}$
}

\author{
Maggie Humm
}

\begin{abstract}
Resumo
A partir do ano 2000, o volume da análise crítica sobre Woolf e a sua relação com o visual tem quadruplicado. O trabalho de pesquisa sobre uma Woolf fotográfica - que inclui a interação de outros fotógrafos com Woolf, como Gisèle Freund, ou a minha própria análise dos álbuns de fotos pessoais de Woolf e Bell - mostra como estas mais recentes questões de Woolf e da fotografia são agora um tema absolutamente central em qualquer análise dos estudos de Virginia Woolf, adquirindo uma importância notória se considerarmos o aspeto interdisciplinar da fotografia e do género.
\end{abstract}

\section{Palavras-chave}

Virginia Woolf; fotografia; Cultura Visual; Estudos Culturais

\begin{abstract}
From 2000, criticism on Woolf and the visual has quadrupled in volume. The research work about a photographic Woolf - which include other photographers' interaction with Woolf such as Gisèle Freund or my own analysis of Woolf and Bell's personal photo albums - shows how these newer issues of Woolf and photography are now absolutely central in any consideration of Virginia Woolf studies, gaining a noticeable importance when we consider the interdisciplinary issue of photography and gender.
\end{abstract}

KeYwORDS

Virginia Woolf; photography; Visual Culture; Cultural Studies

Desde os quinze anos de idade que as fotografias foram o enquadramento do mundo de Woolf. Virginia Woolf escreveu sobre fotografia nos seus diários, cartas e dissertações, e utilizou termos fotográficos em descrições na sua ficção. Antes do casamento, e depois juntamente com Leonard, Woolf tirou, revelou e preservou em álbuns mais de um milhar de fotografias. A fotografia era uma parte constante das vidas dos Woolf, ainda que os seus álbuns fotográficos não contem uma história de vida coerente (Humm, 2005).

Ela transformou habilmente amigos e momentos em imagens artísticas, rodeando-se de amigas e de familiares que eram também fotógrafos enérgicos, tais como Lady

\footnotetext{
'Este artigo, que resume o meu trabalho sobre Woolf e a fotografia (Humm, 2003 \& 2005), é a versão escrita e a edição final de uma palestra que preparei para a conferência internacional "Virginia Woolf and Images: Becoming Photographic (2016), da Société d'Etudes Woolfienne", realizada na Universidade de Toulouse, em 2016: http://sait-france.org/evenements/ virginia-woolf-and-images-becoming-photographic/.
} 
Ottoline Morrell, Vita Sackville-West e a artista Dora Carrington. Aos quinze anos, Woolf utilizava uma máquina fotográfica Frena, tal como revelam as suas cartas a Thoby Stephen e George Duckworth. A Frena, uma câmara de revista, em formato de caixa, lançada em 1896, tinha uma lente de focagem fixa e um manípulo excêntrico, que exigia um operador de câmara dedicado. Na fotografia de Virginia e Julian, tirada por Vanessa Bell, em Blean, em 1910, que faz parte de Snapshots (Humm, 2005, p. 87), Woolf poderá estar com a sua Frena na mão.

A essência das fotografias reside no apelo da experiência ou no evento retratado a um espectador. Woolf, tal como a irmã e a sua tia-avó, a fotógrafa Julia Cameron, convidava frequentemente amigos para partilharem as suas reflexões. As cartas e os diários descrevem uma troca constante de fotografias, em que a fotografia se converte num local de encontro, numa conversa, num aide-mémoires, e, por vezes, em mecanismos de sobrevivência e sedução. Aos 16 anos, as fotografias eram "o melhor presente em que posso pensar" (Nicolson \& Trautmann, 1975, p. 18). Virginia ficava feliz por enviar uma fotografia sua à amiga Emma Vaughan, ainda que fosse "algo como um velho monstro" seu conhecido (Nicolson \& Trautmann, 1975, p.29). Visitar o fotógrafo profissional Beresford para a agora famosa sessão era "um entretenimento" (Nicolson \& Trautmann, 1975, p. 78).

Aos 21 anos, as fotografias dos amigos eram como símbolos eróticos. "Tenho a fotografia de Marny [Madge Vaughan] na minha estante, como uma madonna a quem rezo. Ela traz requinte ao meu quarto, como alfazema nas gavetas - (!!)" (Nicolson \& Trautmann, 1975, p. 88). O primeiro volume da coletânea de cartas de Woolf termina adequadamente com Virginia a enviar a sua fotografia a Leonard. "Gostas desta fotografia? - talvez demasiado imperial, acho eu. Aqui está outra" (Nicolson \& Trautmann, 1975, p. 497). Woolf convidava amigos a partilharem as suas vidas com ela através de fotografias. Ela gostava "muitíssimo" de ter fotografias de bebés "ele é um rapazinho interessante" [Mark, filho de Katherine Arnold-Forster] (Nicolson \& Trautmann, 1975, p. 495). A fotografia de Barbara Bagenal e do filho "tal e qual o pai" está metida no meu livro" e é impossível trocá-la, porque "as minhas apanharam todas o orvalho nebuloso este Verão" (Nicolson \& Trautmann, 1975, p. 6). As fotografias de Bagenal estão montadas sobre cartão no Álbum 2 da Monk House de Woolf, reproduzindo visualmente o modo como Woolf conservava cuidadosamente as suas amizades. Após as suas mortes, as fotografias dos amigos foram importantes memento mori. Pretendendo enviar a Jacques Raverat, o pintor francês, "uma fotografia minha, feita para uma revista banal, chamada Vogue". Após a sua morte, em 1925, ela precisou de fotografias para continuar as suas conversas mentais, e de Gwen Raverat, Woolf pretendia desesperadamente "um instantâneo ou qualquer fotografia dele? Continuo a ter coisas para lhe contar" (Nicolson \& Trautmann, 1977, p.130, pp. 172-173). $\mathrm{Na}$ fotografia da Vogue, Virginia está a usar o vestido da mãe. Woolf acreditava que as fotografias podiam ajudá-la a sobreviver a esses momentos da sua própria vida, destruidores de identidade - as suas doenças incoerentes. Por exemplo, ao escrever a Margaret Llewelyn Davies, em 1915, Woolf "queria dizer que durante aquele tempo terrível" [um ataque de aparente insanidade, que durou uma semana] "eu pensava em ti, e queria olhar para uma fotografia tua, mas tinha receio de pedir!" (Nicolson \& Trautmann, 1976, p. 60). As 
fotografias dos amigos eram essenciais para o próprio sentido de identidade de Woolf. As fotografias dos amigos constituem muitas vezes provas autobiográficas sólidas e visíveis quando sentimentos de perda de identidade se tornam avassaladores.

A criação mútua de imagens também cria relações. Woolf usou fotografias para aliciar Vita Sackville-West. Ao escrever para "Mrs. Nicolson", em 1923, Woolf pedia a Vita que a visitasse para "ver as fotografias da minha tia-avó de Tennyson e de outras pessoas" (Nicolson \& Trautmann, 1977, p. 4). Em 1926, mais desesperadamente, Woolf escreveu à mãe de Vita, Lady Sackville, a pedir o nome do fotógrafo do passaporte de Vita, para "eu própria poder escrever-lhe" a pedir uma cópia da fotografia (Nicolson \& Trautmann, 1977, p. 246). Virginia levou Vita a Londres para ser fotografada para Orlando e usou a desculpa de mais ilustrações para fazer mais visitas a Knole e para mais sessões fotográficas. "Vais almoçar aqui à uma em ponto, na segunda-feira, não vais, e vais trazer os teus enfeites e as roupas. Nessa [Vanessa Bell] quer fotografar-te às 2" (Nicolson \& Trautmann, 1977, p. 435). A fotografia aparece em Orlando, como Orlando, por volta do ano de 1840.

Ao escrever à sua amiga Ethel Smyth, em 1940, Woolf comparou os seus próprios sentimentos subjetivos a um processo fotográfico. "Então como é que eu transfiro estas imagens para o meu sensível cérebro de papel? Porque eu tenho um coração. Sim, e é o coração que faz o com que o papel agarre, como dizem" (Nicolson \& Trautmann, 1980, p. 393). Woolf precisava particularmente de fotografias para escrever. Por exemplo, em 1931 pediu a Vita "uma fotografia de Henry" [o cocker spaniel de Harold Nicolson], "eu peço por uma razão especial, relacionada com uma pequena escapadela", que se tornou o livro Flush, de Woolf (Nicolson \& Trautmann, 1978, p. 380). As fotografias irónicas em Flush e Three Guineas, a amorosa construção das fotografias de Vita e Angelica em Orlando, estabelecem um paralelo com as múltiplas referências a fotografias na ficção de Woolf. Por exemplo em Night and Day Woolf julga as personagens pelas fotografias que elas exibem nas suas casas. Em suma, as fotografias podem ser "apenas um olho", mas possibilitaram a Woolf uma visão mais clara.

\section{OS ESTUDOS DE WOOLF SOBRE FOTOGRAFIA}

O facto de a imaginação de Woolf ser moldada pela fotografia tornou-se um ponto fulcral nos anos 1990, algo indubitavelmente desencadeado pelos desenvolvimentos na crítica literária e nos estudos culturais que se verificaram nessa década, muitas vezes expressos como a viragem para o visual. Os críticos argumentam que Woolf utilizou a fotografia para destabilizar ideias preconcebidas de biografia e que as suas representações textuais refletem a fotografia (Wussow, 1994; Neverow, 1999). A própria prática fotográfica de Woolf tornou-se o foco do meu trabalho (Humm, 1999). Um volume essencial foi a coleção editada por Diane F. Gillespie e Leslie K. Hankins, Virginia Woolf and the Arts, que juntou muito do agora extenso novo trabalho sobre Woolf e o visual, e que incluiu o ensaio ricamente detalhado de Gillespie sobre Woolf e a fotografia (Gillespie \& Hankins, 1985).

A partir de 2000, a análise crítica sobre Woolf e a sua relação com o visual tem quadruplicado em volume, tornando-se ainda mais ampla e abrangente, coincidindo com 
uma nova atenção à arte de Bloomsbury nas galerias públicas. A atenção dada a uma Woolf fotográfica alargou-se, para incluir a interação de outros fotógrafos com Woolf, designadamente Gisèle Freund, e os scrapbooks de Woolf (Luckhurst, 2001; Pawlowski, 2010). Uma pesquisa mais aprofundada nos arquivos incluiu a minha própria análise de álbuns fotográficos e de cinema pessoais de Woolf e Bell (Humm, 2003; Humm, 2005). O trabalho ainda em curso mostra de que modo estas questões mais recentes de Woolf e da fotografia são agora absolutamente centrais em qualquer abordagem aos estudos de Woolf, confirmadas por eventos como a conferência internacional da Société d'Études Woolfiennes, Virginia Woolf and Images: Becoming Photographic (2016) (Dickey: 2010; Cassigneul, 2014), que foi o ponto de partida para este artigo. Por outro lado, a questão de Woolf e da fotografia também se torna uma referência no campo interdisciplinar da cultura visual, assumindo um papel importante na abordagem das apropriações feministas do dispositivo fotográfico.

\section{OS ENSAIOS DE WOOLF}

Woolf escreveu muitos ensaios que versam a fotografia, frequentemente prestando-Ihe atenção mesmo nos ensaios que não abordam diretamente tópicos visuais. Por exemplo, Gold and Iron começa com uma descrição esclarecedora de como revelar fotografias. A voz de Woolf é sempre multitonal, mesmo na breve frase "foi-me dada a oportunidade..." de ver "o novo processo da película a cores" de Friese-Greene, onde ela revela uma clara compreensão da colorização no cinema (Mcneillie, 1986, p. 403). Em Julia Margaret Cameron, Woolf descreve a vida e a carreira da sua tia-avó. A própria prática fotográfica contínua de Woolf é prova da sua compreensão de como a fotografia de Cameron suscita e expressa uma "sensibilidade" (Mcneillie, 1998, p. 381). O uso, por Cameron, dos fundos amorfos e escuros e do sfumato, ou dos contornos pouco definidos, coincide com a recusa de Woolf em criar personagens bidimensionais.

Embora Woolf não fosse cineasta, faz comentários perspicazes sobre a nova arte, sendo o seu ensaio The Cinema o primeiro ensaio britânico sobre o cinema avant-garde (e Woolf viu muitos filmes, incluindo Storm Over Asia, Le Million, e O Monte dos Vendavais). The Cinema, ostensivamente sobre The Cabinet of Dr Caligari, discute uma série de filmes, incluindo documentários e Anna Karenina. O ensaio revela o conhecimento de Woolf dos processos cinematográficos - close-ups em que se veem "os próprios tremores" dos lábios de uma personagem, e o uso de objetos como "seixos numa praia" para sugerir emoções (Mcneillie, 1998, p. 351). Woolf aponta para a ótica inconsciente do cinema, e julga a arte do cinema por mentir, não na sua essência, mas nos processos cinematográficos, em especial na utilização da ausência constitutiva, "nós fitamo-los [pessoas e objetos] tal como eles são quando nós não estamos lá", e como o filme liga os pensamentos e as memórias inconscientes dos espectadores (Mcneillie, 1998, p. 349). Mais tarde, Woolf adota a perspetiva de um fotógrafo modernista em The House of Commons (A Câmara dos Comuns), "olhamos para baixo, para alguns dos chapéus altos mais lustrosos", pressagiando os seus pontos de vista mais feministas de Three Guineas, 
e as suas imagens visuais/políticas das roupas masculinas (Clarke, 2009, p. 325). As modernas tecnologias capacitam Woolf para novas perceções modernistas.

\section{WOOLF, ESCRITA E FOTOGRAFIA}

Virginia Woolf é uma das principais escritoras visuais do século XX. Utiliza frequentemente um vocabulário extraído da fotografia, por exemplo em To the Lighthouse e nos seus contos Blue and Green e Monday or Tuesday. Alguns dos seus livros incluem ilustrações: Flush, Orlando, Roger Fry: A Biography e Three Guineas. A Hogarth Press dos Woolf ensinou-lhe as artes gráficas da formatação e da forma espacial, com a própria Woolf a fazer a composição tipográfica de trinta e quatro livros. E os livros publicados pelos Woolf sobre cinema como, por exemplo, Walking Shadows (1931) de Eric White.

Primeiro, vou examinar as analogias: como as cenas e as descrições na sua escrita coincidem muitas vezes com a sua própria fotografia doméstica e a da família. Depois, quero examinar aquilo que Woolf adotou das linguagens e métodos da fotografia. $E$ isto inclui o uso que ela faz de tropos fotográficos, por exemplo em Flush; porém, o que é mais importante é o modo como o seu conhecimento sobre fotografia a incentivou a encontrar novas formas de representar argumentos políticos, por exemplo em Three Guineas.

\section{Analogias}

Uma das coisas que descobri quando fazia pesquisa para o meu livro Snapshots of Bloomsbury é que existem estreitos paralelismos entre os pormenores das fotografias domésticas tiradas por Virginia Woolf e das fotos que Ihe foram tiradas a ela, e os pormenores descritivos da escrita de Woolf. Muitas vezes, Woolf parece estar a descrever não uma memória real, mas como se estivesse a descrever uma fotografia nos álbuns à sua frente. Por exemplo, as descrições de Woolf, nas suas Reminiscences autobiográficas, da "honestidade" de sua irmã Vanessa, "agarrando-se à verdade com demasiada tenacidade", que Woolf exemplifica através de uma referência do criquete - "ela jogava melhor criquete pelas mesmas razões, com a sua tacada direta", coincidem com uma fotografia tirada na Casa de Talland, a casa de verão da sua infância (Woolf, 1985, p. 31; Humm, 2005, p. 53). A famosa abertura da autobiografia de Woolf, A Sketch of the Past: "começo: a primeira memória. Era de flores vermelhas e púrpura, sobre um fundo preto - o vestido da minha mãe; e ela estava sentada ou num comboio ou num autocarro, e eu estava ao colo dela", o que coincide com a chapa $36 f$ do álbum de fotos de Leslie Stephen, na posse de Woolf quando ela escreveu a sua autobiografia (Woolf, 1985, p. 64). A fotografia era, é claro, a preto e branco e, portanto, além da cena completa, Woolf enfatiza o "fundo preto" do vestido da mãe. A fotografia é a primeira fotografia tirada a Woolf, tornando-se portanto a primeira recordação.

Crucialmente para a fotografia e a escrita posteriores de Woolf, em 1892 a sua irmã Vanessa tirou uma fotografia essencial de Virginia, juntamente com a mãe e o pai, sentados a ler, na Casa de Talland (Humm, 2005, p. 46). Todos os álbuns das três irmãs, o 
de Virginia, o de Vanessa e o da meia-irmã de ambas, Stella, incluem esta fotografia de 1892, em que Virginia olha para Vanessa como operadora de câmara, como se partilhasse uma "cena primitiva". O pai de Woolf também recorda a fotografia no seu Mausoleum Book, escrito acerca da falecida Julia, e inclui-a no seu álbum de fotos (embora date a fotografia de 1893). E a mesma cena é recriada em To the Lighthouse, quando o Sr. e a Sra. Ramsay liam juntos "aqui, ele olhou para ela a ler. Parecia muito tranquila, a ler" e a Sra. Ramsay, uma ou duas frases mais adiante, lendo sobre rosas, "pousando as mãos numa flor e depois noutra", que se assemelham aos pormenores das flores na parte de trás da fotografia (Woolf, 1992, pp. 162-163).

Os ensaios e os textos não-ficcionais de Woolf utilizam frequentemente uma forma dialógica para romperem com uma causalidade direta e chamarem o leitor. Melba Cuddy-Keane argumentou que essa utilização de uma forma dialógica "constitui a maior separação de Woolf" da academia convencional, nos anos de 1920 (Cuddy-Keane, 2003, p. 79). Existem analogias imediatas entre a técnica de Woolf na prosa e as fotografias que os Woolf tiravam nesse tempo. A sua preferência pelos auto-retratos a dois e dos seus amigos constituem uma autobiografia visual dialógica e repetitiva.

Estes pares de sequências repetitivas vão além das convenções de fotografias cândidas ou instantâneas. Na sua utilização da repetição, as fotografias incentivam ao diálogo entre os modelos e entre marido e mulher como operadores de câmara (Humm, 2005, p. 127). O constante emparelhamento de marido e mulher e amigos, ao longo de décadas, é uma prática dialógica; por exemplo, a colocação no álbum das fotografias de John Maynard Keynes e de sua mulher, Lydia, também exagera a qualidade de casal (Humm, 2005, p. 132). São retratos duplos, nos quais cada figura tem uma presença importante. Estas fotografias afastam o espaço amador normal entre o modelo e o fotógrafo.

De modo idêntico, na crítica de Woolf, são frequentes os diálogos de Woolf com o leitor. A introdução do seu Life As We Have Known It faz de nós leitores ativos, porque a narradora tem, ao que parece, uma grande dificuldade em descrever cenas. Ela vê uma mulher "a usar algo como uma corrente" (obviamente uma presidente de câmara) (Woolf \& Clarke, 2009, p. 226). Miss Kidd usa roupas de cor púrpura forte "a cor parecia algo simbólica", a narradora parece não conhecer as cores das sufragistas, e pergunta "para que é que serve tudo isto?" (Woolf \& Clarke, 2009, pp. 230-232).

Outros usos da forma dialógica surgem na interação de Woolf com os escritos de seu pai, Leslie Stephen. Por exemplo, existem paralelismos muito estreitos entre alguns dos ensaios de Woolf e o ensaio Hours in a Library, de Stephen. Sobre o escritor, de Quincey Stephen escreveu: "ele é totalmente incapaz de se concentrar... o mais difuso dos escritores" (Stephen, 1874, p. 230). Sobre de Quincey, Woolf escreve, cinquenta anos depois "ele era profusa e indiscriminadamente loquaz. Discursividade - a doença" (Woolf \& Clarke, 2009, p. 455). Ler os ensaios de Stephen e Woolf em conjunto é como ouvir duas vozes em diálogo e também em desacordo, sobretudo em relação às mulheres escritoras, como George Eliot, quando Stephen elogia as primeiras cenas agrícolas e Woolf argumenta que "confinar George Eliot ao mundo agrícola" faria com que ela "perdesse o seu verdadeiro sabor" (Woolf \& Mcneillie, 1998, p. 177). 


\section{AdoçõEs}

As adoções mais óbvias que Woolf faz nos seus escritos são de tropos fotográficos. Nos anos de 1930 surge uma nova linguagem do modernismo, em resposta a desenvolvimentos em culturas visuais, incluindo o cinema e as tecnologias fotográficas. O novo vocabulário visual do modernismo, formado pelas estratégias fotográficas dos close-ups, perspetivas pouco usuais e fortes contrastes tonais, emerge em The Waves, de Virginia Woolf - onde a luz transforma os objetos. O novo estilo era visivelmente urbano. Os assuntos incluíam altos arranha-céus, cenas de rua e objetos do dia-a-dia, muitas vezes captados com perspetivas dramáticas e contrastes tonais. A escrita modernista era parte de um mundo no qual tecnologias fotográficas ubíquas moldavam a modernidade urbana em imagens dramáticas, com múltiplas perspetivas. Não era realmente de surpreender que Woolf quisesse adotá-las nos seus escritos.

Apesar de esta complexa experiência de tecnologias visuais parecer estar em contradição com um dos mais populares romances de Virginia Woolf dos anos de $1930-$ Flush, todo um romance aparentemente sobre o sentido do olfacto e não da visão, Flush é um romance sobre o cão Flush, pertencente à poetiza do século XIX, Elizabeth Barrett Browning, e à sua vida juntos, contado do ponto de vista do cão. Mas é da leitura de um livro como Flush, aparentemente menos aberto a interpretações visuais, que pode ser visto o impacto crucial da fotografia na modernidade de Woolf.

A escrita de Flush começou e acabou com tecnologias visuais. Conforme indicado, em 16 de setembro de 1931, Woolf escreveu a Vita Sackville-West a pedir-lhe uma fotografia, mas de um outro cão, Pinka, que Woolf dera a Vita e que acabou por se tornar no Flush. Woolf começou por conceber Flush como uma figura visual. "Li as cartas de amor de Browning, e a figura do cão deles fez-me rir; por isso, não consegui resistir a dar-lhe uma Vida" (Woolf, 1979, pp. 161-162). Em outubro de 1933, após o enorme êxito de Flush na Grã-Bretanha e nos Estados Unidos, Woolf estava novamente entusiasmada com as possibilidades visuais de Flush. "É possível que Flush dê um filme" (Bell \& McNeillie, 1982, p. 186). O filme nunca foi feito, mas o realizador Joseph Fiennes deverá rodar Flush em 2017.

As referências ao visual aparecem ao longo de todo o romance. É como se o compromisso com as técnicas representativas da fotografia capacitassem Woolf para representar e terminar Flush como uma série de objetos visuais conectados. "Visualizo este livro agora... como uma série de grandes balões... posso tomar liberdades com a forma da representação" (Bell \& McNeillie, 1982, p. 142). Em Florença, Flush é testemunha da política das ruas, desde cima, a perspectiva típica do fotógrafo urbano modernista. Sob a varanda de Barrett Browning "uma vasta multidão subia a rua, desde baixo... as pessoas na rua - homens sérios, jovens mulheres alegres - beijavam-se e erguiam os filhos bebés às pessoas que estavam nas varandas" (Woolf, 1933, pp. 79-80). A fotografia tinha maximizado os pontos de visão panorâmicos e elevados da cidade, graças a tempos de exposição mais rápidos do obturador.

Flush teoriza tanto através da sua imaginação visual como através do seu sentido do olfato. O incansável esforço de Flush para visualizar aquilo que o rodeia através do fotográfico permite a Woolf criar um distanciamento humorístico. Quando Flush vê o novo bebé de Elizabeth Barrett Browning, pensa: "era um animal vivo. Independentemente de 
todos eles, sem a porta da rua estar aberta, fora de si própria, no quarto, sozinha, a Sra. Browning tinha-se transformado em duas pessoas." (Woolf, 1933, p. 83). Uma perceção fotográfica permite o humor. É precisamente porque o fotográfico faz essas intervenções contínuas em Flush, que Flush, exatamente como outras obras de Woolf, está estruturado por adoções do visual.

Uma adoção muito mais complexa da fotografia ocorre em Three Guineas, obra de Virginia Woolf sobre dar três guinéus àqueles que podem impedir a guerra, e demonstra uma das principais maneiras pelas quais as fotografias e as memórias visuais podem revelar uma subjetividade de género nas diferentes maneiras como Woolf contesta um mundo patriarcal masculino, conforme representado nas fotografias publicadas: um general, arautos, professores universitários, um juiz e um Arcebispo, com a "afetação" feminina das memórias visuais do narrador, de fotografias de atrocidades fascistas, enviadas pelo governo republicano aos apoiantes britânicos, durante a Guerra Civil Espanhola, e que não estão reproduzidas no texto.

$\mathrm{Na}$ minha perspetiva são as fotografias em falta que, de uma forma significativa, moldam a narrativa de Three Guineas, uma obra estruturada por muitas referências a "corpos mortos e casas em ruínas", em que os diferentes olhares do narrador fazem disparar a análise política do patriarcado de Woolf. A fotografia em falta funciona como um ato transacional de memória entre o narrador e o leitor. Woolf consegue isso através de detalhes visuais específicos. Na fotografia em falta, as casas em ruínas assemelham-se ao jogo infantil do Mikado, um jogo de interior. Os corpos "certos" são os das crianças, e as casas continuam a reter "uma gaiola para pássaros", ela própria muitas vezes uma metáfora convincente dos isolamentos privados das mulheres vitorianas (Woolf, 1993, p. 125). Woolf, seguidamente, abrevia o relato detalhado numa única mnemónica frásica, que vai aparecendo ao longo do texto, por exemplo, "a fotografia de casas em ruínas e corpos mortos" (Woolf, 1993, p. 138), ou "imagens de corpos mortos e casas em ruínas" (Woolf, 1993, p. 154). Cada memória das fotografias em falta gera outra, permitindo a Woolf imaginar reformas mais radicais para as mulheres. "Considerem também estas fotografias: são imagens de corpos mortos e casas em ruínas. Por certo que, tendo em conta estas perguntas e estas imagens, há que ponderar com muito cuidado antes de começar a reconstruir a sua faculdade, qual é o objeto da educação (...). Agora, e dado que a História e a Biografia - as únicas evidências disponíveis para um estranho - parecem provar que a educação da velha-guarda", segundo reclama o narrador, não alimenta qualquer "ódio pela guerra", então a nova faculdade deve ser "uma faculdade experimental” (Woolf, 1993, pp. 132-133). Cada memória da imagem em falta dá a Woolf a força necessária para avançar rumo a uma agenda social mais complexa, numa viragem da sua visão de simples defesa da igualdade de oportunidades - porque a agenda profissional masculina só faz com que as pessoas "percam os seus sentidos" (Woolf, 1993, p. 197) - para imaginar novas liberdades culturais e intelectuais, em Outsiders Society. O profundo conhecimento de fotografia de Woolf - a sua constante prática fotográfica, a construção de um álbum fotográfico, e a experiência contínua de ser fotografada ao longo da vida - inspirou-a a escolher a fotografia como um meio gerador em Three Guineas. 
Outros escritos de Woolf influenciados pela fotografia incluem The Years, que é fotográfico na maneira como repensa a relação entre as personagens e o espaço; "Kitty, que alterou o foco dos seus olhos para se ajustar à pequenez da família Robson, foi tomada de surpresa" (Woolf, 2000, p. 60); Martin, de pé, frente à Catedral de St. Paul. "De pé, com as costas comprimidas contra a loja, tentando visualizar a totalidade da Catedral" (Woolf, 2000, p. 199).

\section{ConclusÃo}

A atenção dedicada por Woolf à fotografia é um tema constante no seu trabalho. As suas próprias fotografias são transacionais, contêm trocas e gestos que vão muito além daquilo que normalmente encontramos em álbuns de família, mas que estão em sincronia com um período que experimentou um renascimento da literatura de personalidade, exatamente como Woolf, na ficção, cria frequentemente significado através de gestos das personagens. Para Woolf, por conseguinte, as fotografias não são representações transparentes e não problemáticas do real. Ela utiliza-as para os seus escritos, com adoções e analogias, e as suas próprias fotografias são formas de auto-investigação e representam identidades materiais, subjetivas e culturais, além de serem, é claro, instantâneos de Bloomsbury. /

\section{REFERÊNCIAS BIBLIOGRÁFICAS}

Bell, A. O. \& McNeillie, A. (Eds.) (1982). The Diary of Virginia Woolf, Vol. Four, 1931-1935. Nova lorque: Harcourt Brace Jovanovich.

Cassigneul, A. (2014). Voir, observer, penser: Virginia Woolf et la photo-cinématographie. Tese de Doutoramento, Universidade Toulouse Jean Jaurés, Toulouse, França. Retirado de http://www.theses.fr/2014TOU20048

Clarke, S. (Ed.) (2009). The Essays of Virginia Woolf, Vol. Five, 1929-1932. Londres: The Hogarth Press.

Cuddy-Keane, M. (2003). Virginia Woolf, the Intellectual, and the Public Sphere. Cambridge: Cambridge University Press.

Dickey, C. (2010). Virginia Woolf and Photography. In M. Humm (Ed.) The Edinburgh Companion to Virginia Woolf and the Arts (pp. 375-391). Edinburgo: Edinburgh University Press.

Gillespie, D. F. \& Hankins, L. K. (Eds.) (1985). Virginia Woolf and the Arts. Nova lorque: Pace University Press.

Humm, M. (1999). Virginia Woolf's Photography. Virginia Woolf Bulletin, 1, 19-21.

Humm, M. (2003). Modernist Women and Visual Cultures: Virginia Woolf, Vanessa Bell, Photography and Cinema. New Brunswick, New Jersey: Rutgers University Press.

Humm, M. (2005). Snapshots of Bloomsbury: the Private Lives of Virginia Woolf and Vanessa Bell. New Brunswick, New Jersey: Rutgers University Press.

Luckhurst, N. (2001). Photoportraits: Gisèle Freund and Virginia Woolf. In J. Berman \& J. Goldman (Eds.), Virginia Woolf Out of Bounds (pp. 197-206). Nova Iorque: Pace University Press. 
Marcus, L. (2010). Virginia Woolf as Publisher and Editor: the Hogarth Press. In M. Humm (Ed.), The Edinburgh Companion to Virginia Woolf and the Arts (pp. 280-297). Edimburgo: Edinburgh University Press.

Mcneillie, A. (Ed.) (1986). The Essays of Virginia Woolf, Vol. Three, 1919-1924. Nova lorque: Harcourt Brace Jovanovich.

Mcneillie, A. (Ed.) (1998). The Essays of Virginia Woolf, Vol. Four, 1925-1928. Londres: The Hogarth Press.

Neverow, V. (1999). "Thinking Back Through Our Mothers": Thinking in Common Virginia Woolf's Photographic Imagination and the Community of Narrators in Jacob's Room, A Room of One's Own, and Three Guineas. In J. Mcvicker \& L. Davis (Eds.), Virginia Woolf a Communities: Selected Papers from the Eighth Annual Conference on Virginia Woolf (pp. 65-90). Nova lorque: Pace University Press.

Nicolson, N. \& Trautmann, J. (Eds.) (1975). The Letters of Virginia Woolf: Vol. One, 1888-1912. Nova lorque: Harcourt Brace Jovanovich.

Nicolson, N. \& Trautmann, J. (Eds.) (1976). The Letters of Virginia Woolf: Vol. Two, 1912-1922. Nova lorque: Harcourt Brace Jovanovich.

Nicolson, N. \& Trautmann, J. (Eds.) (1977). The Letters of Virginia Woolf: Vol. Three, 1923-1928. Nova lorque: Harcourt Brace Jovanovich.

Nicolson, N. \& Trautmann, J. (Eds.) (1978). The Letters of Virginia Woolf: Vol. Four, 1929-1931. Nova lorque: Harcourt Brace Jovanovich.

Nicolson, N. \& Trautmann, J. (Eds.) (1979). The Letters of Virginia Woolf: Vol. Five, 1932-1935. Nova lorque: Harcourt Brace Jovanovich.

Nicolson, N. \& Trautmann, J. (Eds.) (1980). The Letters of Virginia Woolf: Vol. Six, 1936-1941. Nova lorque: Harcourt Brace Jovanovich.

Pawlowski, M. (2010). Virginia Woolf and Scrapbooking, In M. Humm (Ed.), The Edinburgh Companion to Virginia Woolf and the Arts (pp. 298-213). Edimburgo: Edinburgh University Press.

Stephen, L. (1874). Hours in a Library. Londres: Smith Elder \& Co.

Woolf, V. (1933). Flush. Londres: Hogarth Press.

Woolf, V. (1985). Moments of Being. Nova lorque: Harcourt Brace Jovanovich.

Woolf, V. (1992). To the Lighthouse. Oxford: Oxford University Press.

Woolf, V. (1993). Three Guineas. Harmondsworth: Penguin.

Woolf, V. (2000). The Years. Londres: Vintage.

Wussow, H. (1994). Virginia Woolf and the Problematic Nature of the Photographic Image. Twentieth Century Literature, XLIL, 1-14.

\section{Nota BiográficA}

Maggie Humm é Professora Emérita de Estudos Culturais na Faculdade de Artes e Indústrias Digitais (The School of Arts and Digital Industries) da Universidade de East 
London. É autora de muitos livros, incluindo Snapshots of Bloomsbury: The Private Lives of Virginia Woolf and Vanessa Bell (Tate Publishing \& Rutgers University Press, 2006) e Modernist Women and Visual Cultures: Virginia Woolf, Vanessa Bell, Photography and Cinema (Edinburgh University Press \& Rutgers University Press, 2002).

E-mail: humm@uel.ac.uk

The School of Arts and Digital Industries, University of East London, University Way, London, E16 2RD, United Kingdom

Submetido: 05-07-2017

Aceite: 30-09-2017 